\title{
Relationship between School Based Stress and Test Anxiety
}

\author{
Jody V. Harpell ${ }^{1} \&$ Jac J. W. Andrews ${ }^{2}$ \\ ${ }^{1}$ Department of Education, Health \& Wellness, Cape Breton University, Sydney, Canada \\ ${ }^{2}$ Division of Applied Psychology, University of Calgary, Calgary, Canada \\ Correspondence: Jody V. Harpell, 158 Terrace Street, Sydney, N.S., B1P 2L7, Canada. E-mail: \\ zarpell@hotmail.com
}

Received: April 19, 2013 Accepted: May 2, $2013 \quad$ Online Published: May 14, 2013

doi:10.5539/ijps.v5n2p74 URL: http://dx.doi.org/10.5539/ijps.v5n2p74

\begin{abstract}
A total of 267 junior and senior high school students (grades 7,8,9,10,11,12; ages 12-19) with relatively more informants identifying as females (57.4\%) compared to males (42.6\%) and more junior high school students (68.3\%) than high school students (31.7\%), responded to the German Test Anxiety Inventory (TAI-G) (Hoddapp \& Benson, 1997) and the School Situation Survey (SSS) (Holmes \& Gable,1989). Pearson product moment analyses yielded significant relationships between most of the TAI-G scales and SSS scales as well as between the scales and sex, age, and grade level. Multiple linear regression analyses significantly identified Academic Stress $(\mathrm{p}<.001)$ and Age $(\mathrm{p}<.05)$ as predicting Worry; Academic Stress $(\mathrm{p}<.001)$, Emotional Stress $(\mathrm{p}<.001)$, and Physiological Stress $(\mathrm{p}<.001)$ predicting Emotionality; Peer Interaction $(\mathrm{p}<.01)$ and Academic Self-Concept $(\mathrm{p}<.001)$ predicting Confidence; Academic Self-Concept $(\mathrm{p}<.001)$ and Behavioral Stress $(\mathrm{p}<.05)$ predicting Interference; and Academic Stress $(p<.001)$, Academic Self Concept $(p<.001)$, Emotional Stress $(p<.01)$, Physiological Stress $(p<.01)$, and Age $(p<.01)$ predicting TA total score; thus supporting the use of the Transactional Model of Stress and Coping as a general framework for understanding TA.
\end{abstract}

Keywords: school stress, test anxiety, adolescence, transactional model, junior high, senior high

\section{Introduction}

The Transactional Model of Stress and Coping (TMSC; Lazarus \& Folkman, 1984) posits that anxiety emerges from stress when one perceives that his or her coping resources will not provide adequate support for dealing with presenting stress. This perceived mismatch between a presenting task and one's ability to deal with that task is considered stressful and can lead to anxiety. Accordingly, test anxiety is best understood through analyses of its' precipitating stressors within schools.

\subsection{School Based Stress}

Educational reform initiatives in North America, the United Kingdom (Polesel, Dulfer, \& Turnbull, 2012) and Australia (Dulfer, Polesel, \& Rice, 2012) have been the focus of a great deal of controversy in recent years. Such reforms include high stakes testing, higher teacher accountability, and pressure to achieve academic goals, to name a few. Advocates of these reforms suggest that these reforms serve to provide evidence of funding effects, track school and student performance, and to increase achievement skills among students. There is much evidence; however, that suggests that these reforms may be leading to negative outcomes among students, teachers and their families. The negative impact of these reforms on student health and well being, especially with regard to student stress, is a common concern emerging from the literature.

Helms and Gable (1989) developed the School Situation Survey (SSS) in order to measure school-related stress. The model includes two broad domains: (1) Sources of Stress (i.e., Academic Stress, Teacher Interactions, Peer Interactions, and Academic Self-Concept) and (2) Manifestations of Stress (i.e., Emotional, Behavioral, and Physiological). According to Helms and Gable (1989), academic stress is a primary source of school-based stress due to (among other things) rising academic achievement standards and continual monitoring of student achievement by way of testing. Another source of school-based stress is negative teacher-student interactions. Teachers report numerous role-related factors that indirectly lead to stressful interactions with students. These include extended working hours, increased paperwork, verbal abuse from students, general lack of support from administration, and poor resources (Smith, 2007). Helms and Gable (1989) also consider student-peer interactions to be a potential source of student stress. For example, adolescents between the ages of 11 and 15 
demonstrate low levels of social support seeking, opting instead to use maladaptive strategies such as resignation, rumination, aggression, and avoidance (Roecker, Dubow, \& Donaldson, 1996). Low academic self-concept is another potential source of school stress. For example, students who are challenged by academics typically have low academic self-concepts that contribute to their stress (Grolnick \& Ryan, 1990; Kistner, Haskett, White, \& Robbins, 1987; Priel \& Lesham, 1990). The Helms and Gable (1989) model of school stress also refers to Manifestations of Stress in schools. These include the emotional (e.g., frustration, anger), behavioral (e.g., fighting, back talk) and physiological (e.g., stomachaches) responses to stress.

\subsection{Test Anxiety}

Test Anxiety consists of interacting phenomenological, physiological, and behavioral responses that occur prior to, during, and following a test (Zeidner, 1998). Typically, the test-anxious person perceives that he or she falls short in intellect or preparedness to successfully complete an evaluation. As noted by Zeidner (1998), in order to understand the etiology of TA, it is important to review the TA in light of the TMSC (Lazarus \& Folkman, 1984). In linking TA with the TMSC, Zeidner (1998) theorizes that the variation in people's appraisals of evaluative situations contributes to differences in test-anxious reactions. Specifically, in evaluative situations, people high in TA are thought to demonstrate more appraisals of threat, whereas those low in TA view the same situations as challenging. As a result, the test-anxious individual is preoccupied with task-irrelevant or failure-focused thoughts, whereas low test-anxious individuals are task-focused. Sarason and Sarason (1990) outline key cognitive characteristics associated with anxiety which include the appraisal of threat, negative outcome focus, obsessions of inadequacy that intrude on task-oriented thought processes, and the expectation that failure will contribute to loss of self-esteem and/or will be scrutinized by others. These cognitions are thought to serve a counterproductive role during evaluative situations. Excessive worrying about failure and the ignition of physiological symptoms (e.g., rapid heartbeat; Liebert \& Morris, 1967), ultimately compound to diminish one's ability to focus on a task (Sarason, 1984), encode information (Mueller, 1979), retrieve important information (Mueller, Elser, \& Rollack, 1993) and ultimately, perform adequately on tests.

Sarason and Mandler's (1952) early research demonstrated a link between anxiety and poor test performance. This was followed by the development of the Test Anxiety Scale for Children (TASC; Sarason et al., 1960) which measured TA among children as a unitary construct. The TASC has been researched extensively for half a century, focusing on factor composition, sex differences, and validity (Ferrando, Varea, \& Lorenzo, 1999). This research suggested that TA is actually a multidimensional construct, usually involving several factors.

Subsequently, the construct of TA was divided into two fundamental components: Worry and Emotionality (Liebert \& Morris, 1967). Worry represented the cognitive concerns relating to failure and consequences of failure, whereas emotionality represented the physiological symptomatology associated with anxiety (e.g., heart racing). Drawing upon this framework, Spielberger (1980) developed the Test Anxiety Inventory (TAI), which became a widely used and popular method of identifying TA for children, as well as for adults. Over a number of years, several studies supported the inclusion of Cognitive Obstruction or Cognitive Interference (McKeachie, 1984; Swanson \& Howell, 1996; Tyron, 1980; Wine, 1971). Sarason (1984) agreed, claiming that both worry (i.e., preoccupation with failure, negative self-talk) and cognitive interference (i.e., disruptive/blocking thoughts) could more accurately describe the cognitive domain of TA. As a result, this factor was represented in Sarason's (1984) Reactions to Tests (RTT) scales, developed through factor analysis on a sample of undergraduate students. In an effort to further develop the construct of TA, Carver and Scheier (1984) proposed that Lack of Confidence should be included in the TA framework. Eventually, these contributions led to the development of a commonly utilized and accepted measure of TA in recent research: the German Test Anxiety Index (TAI-G; Hodapp, 1991, 1995). Ensuing research seeking to validate the psychometric properties of the TAI-G in German and American populations demonstrated high reliability and validity across the various sub-domains (Hodapp, 1991, 1995; Hodapp \& Benson, 1997; Keith, Hodapp, Schermeller-Engel, \& Moosbrugger, 2003; Musch \& Broder, 1999). Overall, the research supported that the components of TA include Worry, Emotionality, Interference, and Lack of Confidence (Hodapp, 1991, 1995), with Worry consistently demonstrating a greater negative impact on test performance compared to the other factors (Deffenbacher, 1980; Hembree, 1988; Liebert \& Morris, 1967). It is hypothesized that worry contributes to cognitive interference, interrupting testing during the preparation stage as well as concentration and recall during testing (Deffenbacher, 1980; Hembree, 1988; Liebert \& Morris, 1967).

\subsection{Rational and Aim of the Study}

The major aim of this study was to investigate the relationship between school based stress and test anxiety. In this regard, the major question to be addressed was: (1) Do the SSS subscales demonstrate relationships with the 
TAI-G subscales and total score? It was predicted that there would be significant relationships and that they would be consistent with the TMSC.

\section{Method}

\subsection{Participants \& Procedures}

The sample for the study consisted of students (grades 7 to 12) from one public school district in eastern Canada. Participants were randomly selected from a volunteer pool. The final analysis was conducted with the participation of 267 students. Demographic characteristics of the student sample were determined for sex, age, and grade. This analysis revealed that relatively more females $(57.4 \%)$ than males $(42.6 \%)$ took part in the study. The age range for students fell between $12(7.2 \%)$ and $19(1.1 \%)$. The grade range for students fell between 7 (20.6\%) and 12 (11.1\%). Participating schools included 10 junior high schools (i.e., grades 7 to 9) and 5 high schools (i.e., grades 10 to 12). As such, representation was slightly more than twice that for younger/junior high (i.e., approximately $68.3 \%$ ) students compared to older/senior high (i.e., approximately $31.7 \%$ ) students.

Once permission from parents, students, and teachers was obtained, one student from each class was randomly selected for participation. The homes of participating students were contacted via phone by the $\left(1^{\text {st }}\right)$ researcher and two research assistants. The measures were administered over the telephone after a session of practice trials during which all research assistants and the researcher agreed upon a specific framework within which to make introductions and administer the scales via telephone. Using telephone correspondence was a necessary condition required by the school district.

\subsection{Measures}

TA was assessed using the English version of the German Test Anxiety Inventory (TAI-G; Hodapp \& Benson, 1997) Studies have indicated that this instrument is psychometrically sound. Confirmatory factor analysis (Hodapp \& Benson, 1997) supported the Liebert and Morris (1967) dimensions of TA (i.e., Worry and Emotionality), as well as Sarason's (1984) Interference, and Carver and Scheier's (1984) Lack of Confidence among a sample of university students. The TAI-G is purported to have strong psychometric properties among college-aged students, as well as mixed samples consisting of college-aged and adolescent students, with each of the four factors (i.e., Worry, Emotionality, Interference, and Lack of Confidence) demonstrating reliability and validity among German and American populations (Hodapp, 1991, 1995; Hodapp \& Benson, 1997; Keith et al., 2003; Musch \& Broder, 1999; Stober, 2004). Studies analyzing criterion validity consistently report that the Worry factor bears the strongest negative relationship with testing performance compared to other factors (Deffenbacher, 1980; Morris \& Liebert, 1969; Seipp, 1996; Zeidner, 1998). Total scores and subscales demonstrate alpha coefficients, ranging from .79 to .94 , providing adequate evidence of internal consistency (Hodapp, 1991).

Student stress was assessed using the School Situation Survey (Helms \& Gable, 1989), a 34-item self-report measure designed for students in grades 4 through 12. Seven scales comprise this instrument. Within the domain of Sources of Stress, Helms and Gable (1989) define teacher interactions as students' subjective perceptions of the attitudes teachers have developed towards them. Academic stress gauges students' feelings towards their academic performance. Peer interactions gauges student-peer relationships and perceptions of the feelings peers have developed towards them. The subscale academic self-concept is designed to assess personal feelings of self-worth, self-esteem, and self-concept with regard to student academic efficacy. Within the domain of Manifestations of Stress, Helms and Gable (1989) define emotional manifestations as a measure of feelings (e.g., shyness, fear). This differs from the traditional definition typically assigned to the concept of emotionality within TA research, where physiological symptoms are the focus. Helms and Gable (1989) include a specific category within this domain, physiological manifestations, which account for such symptoms (e.g., nausea, rapid heartbeat). The final subscale within the Manifestations domain is behavioral manifestations, assessing overt actions or reactions towards others (e.g., striking out, demonstrating disrespect). As outlined in the manual, this instrument demonstrates adequate psychometric properties supporting its dimensional structure, as well as evidence for reliability, validity, and internal consistency (Helms \& Gable, 1989). In terms of internal consistency, alpha coefficients for the subscales range from .68 to .80 . Test-retest reliability coefficients obtained over a 3-week period ranged from .61 to .71 . In terms of validity, the manual reports factor analytic findings supporting the seven-scale structure of the measure.

\section{Results}

Table 1 presents descriptive statistics for the TAI-G and SSS scales. Skewness and kurtosis values were computed to test for the normality of the TAI-G and SSS distributions. All of the skewness and kurtosis values 
were well within the acceptable range for all scales of the TAI-G and SSS. Cronbach's alpha internal consistency reliabilities for the TAI-G and SSS scales are presented in Table 2. Almost all reliabilities for the SSS subscales were above .70 with the exceptions of Behavioral Stress $(\alpha=.62)$ and Physiological Stress $(\alpha=.63)$. All of the reliabilities for the TAI-G scales were .80 and above except for Worry $(\alpha=.77)$.

Table 1. Descriptive statistics for TAI-G and SSS scales

\begin{tabular}{|c|c|c|c|c|}
\hline & $N$ & $M$ & $S D$ & Range \\
\hline \multicolumn{5}{|l|}{ TAI-G (student ratings) } \\
\hline Worry & 263 & 26.93 & 5.48 & $13-40$ \\
\hline Emotionality & 261 & 14.55 & 4.51 & $8-32$ \\
\hline Lack of confidence & 263 & 10.99 & 3.76 & $6-23$ \\
\hline Interference & 262 & 11.54 & 4.05 & $6-24$ \\
\hline Total & 260 & 63.99 & 12.20 & $33-108$ \\
\hline \multicolumn{5}{|l|}{ TAI-G (parent ratings) } \\
\hline Worry & 267 & 26.75 & 5.71 & $13-40$ \\
\hline Emotionality & 264 & 14.27 & 4.99 & $8-30$ \\
\hline Lack of confidence & 265 & 10.74 & 3.82 & $6-24$ \\
\hline Interference & 266 & 11.40 & 4.34 & $6-24$ \\
\hline Total & 263 & 63.23 & 13.36 & $35-102$ \\
\hline \multicolumn{5}{|l|}{ TAI-G (teacher ratings) } \\
\hline Worry & 167 & 25.96 & 6.36 & $10-53$ \\
\hline Emotionality & 165 & 12.72 & 3.92 & $8-28$ \\
\hline Lack of confidence & 166 & 12.60 & 4.70 & $6-23$ \\
\hline Interference & 166 & 9.85 & 3.92 & $6-22$ \\
\hline Total & 165 & 61.25 & 12.07 & $36-97$ \\
\hline \multicolumn{5}{|c|}{ School Situation Survey (student ratings) } \\
\hline \multicolumn{5}{|l|}{ Sources of stress } \\
\hline Teacher interactions & 262 & 11.70 & 3.98 & $6-26$ \\
\hline Academic stress & 262 & 9.04 & 3.08 & $3-15$ \\
\hline Peer interactions & 262 & 9.90 & 3.40 & $6-22$ \\
\hline Academic self-concept & 262 & 8.56 & 3.01 & $4-18$ \\
\hline \multicolumn{5}{|l|}{ Manifestations of stress } \\
\hline Emotional stress & 262 & 11.63 & 3.68 & $6-24$ \\
\hline Behavioral stress & 260 & 9.65 & 2.77 & $6-19$ \\
\hline Physiological stress & 261 & 6.24 & 2.54 & $3-15$ \\
\hline
\end{tabular}

Table 2. Internal consistency (Standardized Alpha) for TAI-G and SSS scales

\begin{tabular}{lccc}
\hline & $N$ & Number of items & Reliability \\
\hline TAI-G & & & \\
Worry & 263 & 10 & .77 \\
Emotionality & 261 & 8 & .80 \\
Lack of confidence & 263 & 6 & .84 \\
\hline
\end{tabular}




\begin{tabular}{lccc}
\hline Interference & 262 & 6 & .84 \\
Total & 260 & 30 & .86 \\
School Situation Survey & & & \\
Sources of stress & & & .72 \\
Teacher interactions & 262 & 6 & .77 \\
Academic stress & 262 & 3 & .71 \\
Peer interactions & 262 & 6 & .78 \\
Academic self-concept & 262 & 4 & .77 \\
Manifestations of stress & & & .62 \\
Emotional stress & 262 & 6 & .63 \\
Behavioral stress & 260 & 6 & \\
Physiological stress & 261 & 3 & \\
\hline
\end{tabular}

\section{Correlational Analyses}

Pearson product moment correlation coefficients between all TAI-G and all SSS scales were computed and yielded significant positive linear relationships between most of the TAI-G scales and most SSS scales (see Table 3 ). For practical purposes, only the exceptions will be noted. There was no significant relationship between Worry and Teacher Interactions or Peer Interactions. The analysis did reveal a significant negative correlation between Worry and Behavioral Stress $(r=-.13, p<.05)$. There was no significant relationship determined between Emotionality and Behavioral Stress, nor between the TAI-G total score and Behavioral Stress. Table 4 presents the results of correlational analysis investigating relationships between the scales and sex, age, and grade level. In this analysis males were coded 0 and females coded 1 . As such, positive correlations specify higher female scores, whereas negative correlations specify higher male scores. Results for sex established a significant correlation with Worry, Emotionality, TAI-G Total Score, Academic Stress, Behavioral Manifestations of School Stress, and Physiological Manifestations of School Stress. These relationships are characterized by higher scores for females on the factors of worry $(\mathrm{r}=.20, \mathrm{p}<.01)$, Emotionality $(\mathrm{r}=.21, \mathrm{p}<.01)$, TAI-G Total Score $(\mathrm{r}=.18 . \mathrm{p}, .01)$, Academic Stress $(\mathrm{r}=.26 . \mathrm{p}<.001)$, and Physiological Manifestations of School Stress $(\mathrm{r}=.22$, $\mathrm{p}<.01)$, and higher scores for males on Behavioral manifestations of School Stress $(\mathrm{r}=-.26 . \mathrm{p}<.001)$. The results for age showed a significant correlation with Worry, as well as Academic Self - Concept. These relationships are characterized by higher Worry among younger students $(\mathrm{r}=-.13, \mathrm{p}<.05)$ and higher Academic Self Concept scores among older students $(\mathrm{r}=.12, \mathrm{p}<.05)$. Results for grade level were congruent with patterns of significant correlations established for age.

Table 3. Correlations between all TAI-G and SSS subscales

\begin{tabular}{lllllll}
\hline Subtests \& Total Scores & 1 & 2 & 3 & 4 & 5 & 6 \\
\hline 1. Worry & -- & & & & & \\
2. Emotionality & $.45^{* * *}$ & -- & & & & \\
3. Lack of confidence & .03 & $.25^{* * *}$ & -- & & & \\
4. Interference & $.15^{*}$ & $.42^{* * *}$ & $.44^{* * *}$ & -- & & \\
5. Teacher interactions & .03 & $.17^{* *}$ & $.34^{* * *}$ & $.41^{* * *}$ & -- & \\
6. Academic stress & $.61^{* * *}$ & $.52^{* * *}$ & $.31^{* * *}$ & $.28^{* * *}$ & $.21^{* *}$ & -- \\
7. Peer interactions & -.01 & $.16^{*}$ & $.30^{* * *}$ & $.25^{* * *}$ & $.30^{* * *}$ & .08 \\
8. Academic self-concept & $.15^{*}$ & $.19^{* *}$ & $.52^{* * *}$ & $.50^{* * *}$ & $.36^{* * *}$ & $.32^{* * *}$ \\
\hline
\end{tabular}




\begin{tabular}{lllllll}
\hline 9. Emotional stress & $.29^{* * *}$ & $.51^{* * *}$ & $.29^{* * *}$ & $.35^{* * *}$ & $.38^{* * *}$ & $.48^{* * *}$ \\
10. Behavioral stress & $-.13^{*}$ & .03 & $.16^{*}$ & $.28^{* * *}$ & $.51^{* * *}$ & -.08 \\
11. Physiological stress & $.26^{* * *}$ & $.48^{* * *}$ & $.22^{* * *}$ & $.28^{* * *}$ & $.24^{* * *}$ & $.44^{* * *}$ \\
12. TAI-G total score & $.68^{* * *}$ & $.79^{* * *}$ & $.56^{* * *}$ & $.69^{* * *}$ & $.32^{* * *}$ & $.65^{* * *}$ \\
Subtests \& Total Scores & 7 & 8 & 9 & 10 & 11 & \\
7. Peer interactions & -- & & & & & \\
8. Academic self-concept & $.17^{* *}$ & -- & & & \\
9. Emotional stress & $.28^{* * *}$ & $.19^{* *}$ & -- & & \\
10. Behavioral stress & $.19^{* *}$ & $.14^{*}$ & $.17^{* *}$ & -- & \\
11. Physiological stress & $.28^{* * *}$ & $.16^{*}$ & $.56^{* * *}$ & .08 & - & \\
12. TAI-G total score & $.23^{* * *}$ & $.46^{* * *}$ & $.52^{* * *}$ & .10 & $.46^{* * *}$ & \\
\hline
\end{tabular}

Note. Sample sizes ranged from $N=258$ to $263 .{ }^{*} p<.05 .{ }^{* *} p<.01 .{ }^{* * *} p<.001$.

Table 4. Correlations between TAI-G and SSS Subscales with sex, age, and grade level

\begin{tabular}{llll}
\hline & Sex & Age & Grade level \\
\hline 1. Worry & $.20^{* *}$ & $-.13^{*}$ & $-.14^{*}$ \\
2. Emotionality & $.21^{* *}$ & -.05 & -.04 \\
3. Lack of confidence & .08 & .01 & .02 \\
4. Interference & -.01 & -.00 & -.00 \\
5. Teacher interactions & -.06 & .00 & -.02 \\
6. Academic stress & $.26^{* * *}$ & -.06 & -.06 \\
7. Peer interactions & -.04 & .02 & .04 \\
8. Academic self-concept & .08 & $.12^{*}$ & $.14 *$ \\
9. Emotional stress & $.16^{*}$ & .06 & .07 \\
10. Behavioral stress & $-.26^{* * *}$ & .12 & .09 \\
11. Physiological stress & $.22^{* *}$ & .04 & .06 \\
12. TAI-G total score & $.18^{* *}$ & -.08 & -.07
\end{tabular}

Note. Sex is coded a $0=$ Male and $1=$ Female so that positive correlations indicate higher scores for females and negative correlations indicate higher scores for males. Sample sizes ranged from $N=241$ to $263 .{ }^{*} p<.05$. ${ }^{* *} p$ $<.01 .{ }^{* * *} p<.001$.

\section{Regression Analyses}

Multiple linear regression analyses were conducted on the sample designating all seven SSS subscales, sex, and age as predictor variables and TAI-G subscales and the TAI-G total score as criterion variables. Separate regressions were computed for each TAI-G. For example, the first regression used the TAI-G Worry subscale as 
the criterion variable. The seven SSS subscales, sex, and age were entered as the predictor variables. The next regression used a different TAI-G subscale as the criterion variable. Each regression used the same predictors. Before computing regressions, variables were tested to be sure that the assumptions for regression analyses were met. All skewness and kurtosis values for all variables were well within the acceptable range. Due to some inadequate reliabilities (noted earlier), adjusted R-squared values are provided in addition to the non-adjusted $\mathrm{R}$-squared values for each regression. The assumption of a linear relationship between independent and dependent variables and the assumption of homoscedasticity were tested by plotting the relationship between the residuals and the standardized predicted value of the dependent variable for each regression. For each regression, the residuals were randomly distributed in no noticeable patterns on either side of zero, indicating that there were no violations of linearity or homoscedasticity.

The first multiple regression examined the TAI-G Worry subscale scores as a function of the seven SSS subscales, sex, and age. The overall model was significant, $F(9,231)=19.04, p<.001$, accounting for $42.6 \%$ of the variance in Worry (adjusted R-squared value was 40.3\%). The analysis identified Academic Stress $(p<.001)$ and age $(p<.05)$ as significant predictor variables, with higher Academic sSress and younger student age predicting higher Worry scores. This pattern remained even when controlling for sex and age. A second multiple regression examined the TAI-G Emotionality subscale scores as a function of SSS scales, sex, and age. The overall model was significant, $F(9,229)=23.53, p<.001$, accounting for $48.0 \%$ of the variance in Emotionality (adjusted R-squared value was 46.0\%). The analysis identified Academic Stress $(p<.001)$, Emotional Stress $(p$ $<.001)$, and Physiological Stress $(p<.001)$ as significant predictor variables, with higher stress scores predicting higher Emotionality scores. These patterns remained even when controlling for sex and age .A third multiple regression examined the TAI-G Lack of Confidence subscale scores as a function of SSS scales, sex, and age. The overall model was significant, $F(9,231)=14.22, p<.001$, accounting for $35.6 \%$ of the variance (adjusted R-squared value was 33.1\%). The analysis identified Peer Interactions $(p<.01)$ and Academic Self-Concept $(p$ $<.001)$ as significant predictor variables, with higher Peer Interactions or Academic Self-Concept scores predicting higher Lack of Confidence scores. These patterns remained even when controlling for sex and age. A fourth multiple regression examined the TAI-G Interference subscale scores as a function of SSS scales, sex, and age. The overall model was significant, $F(9,230)=17.69, p<.001$, accounting for $40.9 \%$ of the variance (adjusted R-squared value was 38.6\%). The analysis identified Academic Self-Concept $(p<.001)$ and Behavioral Stress $(p<.05)$ as significant predictor variables, with higher Academic Self-Concept or Behavioral Stress scores predicting higher Interference scores. These patterns remained even when controlling for sex and age. A final multiple regression examined the TAI-G total subscale scores as a function of SSS scales, sex and age. The overall model was significant, $F(9,228)=44.37, p<.001$, accounting for $63.7 \%$ of the variance (adjusted R-squared value was 62.2\%). The analysis identified Academic Stress $(p<.001)$, Academic Self-Concept $(p$ $<.001)$, Emotional Stress $(p<.01)$, Physiological Stress $(p<.01)$ and age $(p<.01)$ as significant predictor variables, with higher SSS scores on those scales and younger age predicting higher TAI-G total scores. These patterns remained even when controlling for sex and age.

\section{Discussion}

The results of the correlational analyses yielded significant positive linear relationships between most of the TAI-G scales and most SSS scales. These results are highly consistent with predictions derived from the Transactional Model of Stress and Coping; thus providing significant evidence for the use of this model as a theoretical foundation for the study of TA. The results yielded positive relationships between females and Worry, Emotionality, TAI-G Total Score, Academic Stress, and Physiological Manifestations of School Stress, as well as a significant relationship between males and Behavioral Manifestations of School Stress. These findings corroborate previous research findings and suggest a female predisposition for developing TA (Ferrando et al., 1999; Gierl \& Rogers, 1996; Hembree, 1988; Seipp \& Schwarzer, 1996; Wren \& Benson, 2004; Zeidner \& Schleyer, 1999). In this regard, this study suggests that the TAI-G factors of Worry and Emotionality, as well as the Total Score, present particular problems for females. Results associated with the SSS indicate that academic stress is present among females when they endorse Worry and Emotionality. Furthermore, the SSS results indicate that females experience Physiological Manifestations of School Stress, whereas males experience Behavioral Manifestations of School Stress. The results also indicate that although females endorse Academic School Stress to a greater degree than males, as well as TA factors of Worry and Emotionality, these problems among females may easily go unnoticed by outside observers compared to males because females appear to experience stress and anxiety symptoms physiologically and by worrying, whereas males tend to act out.

The results for age and grade established a significant correlation with Worry, as well as Academic Self-Concept. These relationships are characterized by higher Worry scores among younger students and higher Academic 
Self-Concept scores among older students. Results for grade level were congruent with the patterns of significant correlations established for age. These results corroborate the Manly and Rosemire (1972) study, which suggested that TA prevalence (in this case Worry), is highest at the junior high level compared to the senior high level. Based on the TMSC, this decline in Worry would theoretically result from a decline in stress. From the results of this study, there appears to be an increase in Academic Self Concept among older adolescents, which may account for the decrease in Worry scores among older teens. Compared to older teens, it would appear that the cognitive component of negative outcome focus (i.e., Worry) may present a particular problem among younger teens, especially with regard to how their skills in school are assessed. The results call for further research investigating the possibility that better transitional, as well as emotional supports for students from the elementary levels of education to junior high might help alleviate fear of failure in school and develop a healthy Academic Self-Concept at an earlier age.

The results from the first and second multiple regressions showed that higher Academic Stress was predictive of higher Worry and higher Emotionality. Thus, one can also say that Worry and Emotionality scores differ as a function of academic stress scores - students with higher Academic Stress scores will have higher Worry and Emotionality scores, and students with lower Academic Stress scores will have lower Worry and Emotionality scores. This data suggests that the original two-factor model including Worry and Emotionality (Liebert \& Morris, 1967) of TA is subject to variation as a function of academic stress. This is especially important to know because Worry is considered the most influential TA factor, presenting the most significant barrier to actual testing performance compared to the other factors (Deffenbacher, 1980; Hembree, 1988; Liebert \& Morris, 1967; Mueller, 1993). Consistent with the TMSC, intervention strategies should aim toward alleviating Academic Stress among students in an effort to reduce levels of Worry and Emotionality and, possibly, enhance test performance. Future research should be conducted to examine the efficacy of such interventions.

A third multiple regression showed that School Stressors, Peer Interaction, and Academic Self-Concept were predictive of Lack of Confidence on the TAI-G. From the theoretical perspective of the TMSC, these results suggest that negative peer interactions and poor academic self-concept may diminish one's confidence in his or her ability to be successful on tests. This corroborates previous research suggesting that academic self-confidence is enhanced through peer support (Sarason \& Sarason, 1994). Moreover, it suggests that social supports during testing might boost one's confidence and lead to better test performance. The data also suggests that intervention strategies aimed at developing student confidence with respect to testing should focus on developing adaptive peer interactions.

The results also revealed that school stress associated with poor academic self-concept also predicted Lack of Confidence towards testing. This is not surprising because both subscales are measuring constructs that are very much alike. Academic self-concept is measuring a broader school stress associated with confidence in one's ability to be successful in school, whereas Lack of Confidence is measuring anxiety associated with confidence in one's ability to be successful in school tests. The finding does, however, suggest that the Lack of Confidence factor of TA is possibly a subcomponent of a broader, more generalized problem related to a poor academic self-concept. In other words, Lack of Confidence towards testing may not be specific to testing situations alone.

A fourth multiple regression showed that school stress associated with Academic Self-Concept was predictive of higher problems associated with the TA factor Interference. During the early development of the construct of TA, several studies supported the inclusion of Cognitive Obstruction or Cognitive Interference (McKeachie, 1984; Swanson \& Howell, 1996; Tyron, 1980; Wine, 1971). This study lends further support to the separation of Worry and Cognitive Interference into two distinct factors of the cognitive domain of TA. Specifically, the first multiple regression indicated that Worry was predicted by academic stress. Academic stress did not, however, predict Cognitive Interference in this study. Instead, this analysis demonstrated that school stress associated with academic self-concept was a predictor of Cognitive Interference. This finding suggests that problems associated with academic self-concept could generate intrusive thoughts that might diminish one's concentration levels during tests. This pattern, however, does not seem to be associated with failure focused thoughts because it is not predictive of the Worry factor of the TAI-G. Further research should investigate what types of thoughts are generated when students are experiencing problems with academic self-concept. If not Worry/failure focused, then there must be other intrusive thoughts that interfere with concentration levels and possibly test performance.

This analysis also demonstrated that Behavioral Manifestations of School Stress predicts Cognitive Interference on the TAI-G. This seems plausible, as maladaptive overt behavioral reactions to school stress could very well divert from one's focus during testing. According to TSMC, this result suggests that interventions designed to enhance concentration during testing by reducing cognitive interference should target stressors associated with academic self-concept and provide alternative strategies to maladaptive behavioral reactions to school stress. 
Future studies should investigate the impact of such interventions on Cognitive Interference and actual testing performance.

A final multiple regression indicated that higher scores on Academic Stress, Academic Self-Concept, Emotional Manifestations of School Stress, Physiological Manifestations of School Stress, and younger age were predictive of higher TAI-G total scores. Since academic progress is often gauged through testing in school, and the TMSC holds that stress precipitates anxiety, it stands to reason that Academic Stress would predict general TA. This underscores the need to design intervention strategies to reduce academic stress in schools. Further research is required to determine how this might occur. Problems associated with Academic Self-Concept also predicted the TAI-G Total Score, suggesting that a diminished sense of one's ability to be successful in academics may be facilitative of TA. Therefore, enhancing academic self-concept should be included in intervention strategies designed to reduce TA. Further research should investigate how this can be achieved, as well as whether such interventions impact testing performance.

The results also indicated that Emotional and Physiological Manifestations of school stress predict the TAI-G total score. In other words, emotional reactions to stress (e.g., anger, crying, and frustration) and bodily symptoms (e.g., stomachaches, headaches) appear to impact the TAI-G total score, again underscoring the need to develop interventions that provide students with alternative coping strategies. With regard to emotional reactions, students may benefit from learning to react to school stress in a more adaptive manner. With regard to physiological reactions, students may benefit from learning relaxation strategies. Finally, younger age predicted the TAI-G total score, suggesting that younger students demonstrate difficulties with general TA to a greater extent than their older counterparts. Again, this underscores the need to reduce school stress and anxiety from very early on in students' school careers.

\section{Conclusion}

Using the TMSC as a theoretical guide, this study demonstrated some very important relationships between various types of school stress and the four factors of TA. Future research should be directed toward corroborating these findings.

\section{References}

Carver, C. S., \& Scheier, M. F. (1984). Self-focused attention in test-anxiety: A general theory applied to a specific phenomenon. In H. M. van der Ploeg, R. Schwartzer, \& C. D. Spielberger (Eds.), Advances in test anxiety research (vol. 3, pp. 3-20). Swets \& Zeitlinger, Lisse, The Netherlands.

Deffenbacher, J. L. (1980) Worry and emotionality in test anxiety. In I. G. Sarason (Ed.), Test anxiety: Theory, research and application. (pp. 111-128) Hillsdale, New Jersey: Erlbaum.

Dulfer, N., Polesel, J., \& Rice, S. (2012). The Experience of Education: The impacts of high stakes testing on school students and their families - an educator's perspective. The Whitlam Institute, Sydney. Retrieved April 30, 2013, from http://www.whitlam.org/_data/assets/pdf_file/0010/409735/High_Stakes_Testing_An_Educators_Perspecti ve.pdf

Ferrando, P. J., Varea, M. D., \& Lorenzo, U. (1999). A psychometric study of the Test Anxiety Scale for Children in a Spanish sample. Personality and Individual Differences, 27(1), 37-44. http://dx.doi.org/10.1016/S0191-8869(98)00227-X

Gierl, M. J., \& Rogers, W. T. (1996). A confirmatory factor analysis of the Test Anxiety Inventory using Canadian high school students. Educational and Psychological Measurement, 56, 315-324. http://dx.doi.org/10.1177/0013164496056002012

Grolnick, W. S., \& Ryan, R. M. (1990). Self-perceptions, motivation, and adjustment in learning disabled children: A multiple group comparison study. Journal of Learning Disabilities, 23, 177-184. http://dx.doi.org/10.1177/002221949002300308

Helms, B. J., \& Gable, R. K. (1989). School situations survey: Manual. Consulting Psychologists Press, California.

Hembree, R. (1988). Correlates, causes, effects, and treatment of test anxiety. Review of Educational Research, 58, 47-77. http://dx.doi.org/10.3102/00346543058001047

Hodapp, V. (1991). Das Prufungsangstlichkeitsinventar TAI-G: Eine erweiterte und modifizierte Version mit vier Komponenten [The Test Anxiety Inventory TAI-G: An extended and modified version with four components]. Zeitschrift fur Padagogische Psychologie, 5, 121-130. 
Hodapp, V. (1995). The TAI-G: A multidimensional approach to the assessment of test anxiety. In C. Schwarzer, \& M. Zeidner (Eds.), Stress, anxiety, and coping in academic settings (pp. 95-130). Francke, Tubingen, Germany.

Hodapp, V., \& Benson, J. (1997). The multidimensionality of test anxiety: A test of different models. Anxiety, Stress and Coping, 10, 219-244. http://dx.doi.org/10.1080/10615809708249302

Keith, N., Hodapp, V., Schermelleh-Engel, K., \& Moosbrugger, H. (2003). Cross-sectional and longitudinal confirmatory factor models for the German Test Anxiety Inventory: A construct validation. Anxiety, Stress, and Coping, 16, 251-270. http://dx.doi.org/10.1080/1061580031000095416

Kistner, J., Haskett, M., White, K., \& Robbins, F. (1987). Perceived competence and self-worth of LD and normally achieving students. Learning Disability Quarterly, 10(1), 37-44. http://dx.doi.org/10.2307/1510753

Lazarus, R. S., \& Folkman, S. (1984). Stress, appraisal, and coping. New York: Springer.

Liebert, R. M., \& Morris, L. W. (1967). Cognitive and emotional components of test anxiety: A distinction and some initial data. Psychological Reports, 20, 975-978. http://dx.doi.org/10.2466/pr0.1967.20.3.975

Lufi, D., Okasha, S., \& Cohen, A. (2004). Test anxiety and its effect on the personality of students with learning disabilities. Learning Disabilities Quarterly, 27, 176-183. http://dx.doi.org/10.2307/1593667

Manley, J., \& Rosemier, R. (1972). Developmental trends in general and test anxiety among junior and senior high school students. The Journal of Genetic Psychology, 120, 219-226. http://dx.doi.org/10.1080/00221325.1972.10532235

McKeachie, W. J. (1984). Does anxiety disrupt information processing or does poor information processing lead to anxiety? International Review of Applied Psychology, 33, 187-203. http://dx.doi.org/10.1111/j.1464-0597.1984.tb01428.x

Morris, L. W., \& Liebert, R. M. (1969). Effects of Anxiety on Timed and Untimed Intelligence Tests: Another Look. Journal of Consulting and Clinical Psychology, 240-244. http://dx.doi.org/10.1037/h0027164

Mueller, J. H. (1979). Test anxiety and the encoding and retrieval of information. In I. G. Sarason (Ed.), Test Anxiety: Theory, Research \& Applications. Hillsdale, NJ: Laurence Erlbaum Associates.

Mueller, J. H., Elser, M. J., \& Rollack, D. N. (1993). Test anxiety and implicit memory. Bulletin of the Psychonomic Society, 31(6), 531-533.

Musch, J., \& Broder, A. (1999). Psychometrische Eigenschaften und Validitat des multidimensionalen Prufungsangstlichkeitsinventars TAI-G [Psychometric properties and validity of the multidimensional test anxiety inventory TAI-G]. Zeitschrift fur Padagogische Psychologie, 13, 100-105. http://dx.doi.org/10.1024//1010-0652.13.12.100

Polesel, J., Dulfer, N., \& Turnbull, M. (2012). The Experience of Education: The impacts of high stakes testing on school students and their families - literature review. The Whitlam Institute, Sydney.

Priel, B., \& Leshem, T. (1990). Self-perceptions of first- and second-grade children with learning disabilities. Journal of Learning Disabilities, 23, 637-642. http://dx.doi.org/10.1177/002221949002301013

Roecker, C. E., Dubow, E. F., \& Donaldson, D. (1996). Cross-situational patterns in children's coping with observed interpersonal conflict. Journal of Clinical Child Psychology, 25, 288-299. http://dx.doi.org/10.1207/s15374424jccp2503_5

Sarason, I. G. (1984). Stress, anxiety, and cognitive interference: Reactions to tests. Journal of Personality and Social Psychology, 46, 929-938. http://dx.doi.org/10.1037/0022-3514.46.4.929

Sarason, S. B., Davidson, K. S., Lughthall, F. F., Waite, R. R., \& Ruebush, B. K. (1960). Anxiety in elementary school children. New York, NY: Wiley.

Sarason, I. G., \& Sarason, B. R. (1990). Test anxiety. In H. Leitenberg (Ed.), Handbook of social and evaluation anxiety (pp. 475-496). New York: Plenum.

Sarason, B. R., \& Sarason, I. G. (1994). Assessment of social support. In S. A. Shumaker, \& S. M. Czajkowski (Eds.), Social support and cardiovascular disease (pp. 41-63). New York: Plenum Press.

Sarason, S. B., \& Mandler, G. (1952). Some correlates of test anxiety. Journal of Consulting and Clinical Psychology, 47, 810-817. 
Seipp, B., \& Schwarzer, C. (1996). Cross-cultural anxiety research: A review. In C. Schwarzer, \& M. Zeidner (Eds.), Stress, anxiety, and coping in academic settings (pp. 13-68). Tubingen, Germany: Francke-Verlag.

Smith, T. (2007). How do state level induction and standards based reform policies affect induction experiences and turnover among new teachers. American Journal of Education, 113, 273-311. http://dx.doi.org/10.1086/510168

Spielberger, C. D. (1980). Preliminary professional manual for the Test Anxiety Inventory. Palo Alto, CA: Consulting Psychologists Press.

Stober, J. (2004). Dimensions of test anxiety: Relations to ways of coping with pre-exam anxiety and uncertainty. Anxiety, Stress, \& Coping, 17(3), 213-226. http://dx.doi.org/10.1080/10615800412331292615

Swanson, S., \& Howell, C. (1996). Test anxiety in adolescents with learning disabilities and behavior disorders. Exceptional Children, 62, 389-397.

Tyron, G. S. (1980). The measurement and treatment of test anxiety. Review of Educational Research, 50, 343-372. http://dx.doi.org/10.3102/00346543050002343

Wine, J. D. (1971). Test anxiety and direction of attention. Psychological Bulletin, 76, 92-104. http://dx.doi.org/10.1037/h0031332

Wren, D. G., \& Benson, J. (2004). Measuring test anxiety in children: Scale development and internal construct validation. Anxiety, Stress and Coping, 17(3), 227-240. http://dx.doi.org/10.1080/10615800412331292606

Zeidner, M. (1998). Test anxiety: The state of the art. New York: Plenum Press.

Zeidner, M., \& Schleyer, E. (1999). Test anxiety in intellectually gifted students. Anxiety, Stress, and Coping, 12, 163-189. http://dx.doi.org/10.1080/10615809908248328 